Brazilian Journal

of Chemical

ISSN 0104-6632

Printed in Brazil

Engineering

www.scielo.br/bjce

Vol. 35, No. 02, pp. 383 - 394, April - June, 2018

dx.doi.org/10.1590/0104-6632.20180352s20160280

(cc) BY

\title{
DENSITY, VISCOSITY AND EXCESS PROPERTIES OF BINARY MIXTURES OF PROTIC IONIC LIQUID (2-HDEAF, 2-HDEAA) + WATER AT DIFFERENT TEMPERATURES
}

\author{
Regiane Silva Pinheiro ${ }^{1, *}$, Francisca Maria Rodrigues Mesquita ${ }^{1}$, Filipe \\ Xavier Feitosa ${ }^{1}$, Hosiberto Batista de Sant'Ana ${ }^{1}$ and Rílvia Saraiva de \\ Santiago-Aguiar ${ }^{1}$ \\ ${ }^{1}$ Departamento de Engenharia Química, Universidade Federal do Ceará - CEP: 60440-554 - \\ Fortaleza/CE, Brasil.
}

(Submitted: April 30, 2016; Revised: February 9, 2017; Accepted: April 10, 2017)

\begin{abstract}
Over the last decade, ionic liquids (IL) have attracted considerable attention for their potential to replace traditional volatile organic solvents due to their well-known physico-chemistry properties. This is an important topic for industrial applications today, and have been the subject of extensive literature studies. Nevertheless, there is still a lack of experimental thermodynamics data on aqueous mixtures, i.e., ionic liquids + water, especially volumetric and transport properties. These data could provide essential information about interactions and molecular phenomena in such mixtures. To investigate volumetric and transport properties for ionic liquids + water, density and viscosity data of the protic ionic liquids 2-hydroxydiethanolamine formate (2-HDEAF), 2-hydroxydiethanolamine acetate (2-HDEAA), water and their binary mixtures were measured at $\mathrm{T}=(293.15$ to 343.15) K and atmospheric pressure. Excess molar volumes and deviation of viscosity were computed from experimental density and viscosity values and were fit to the Redlich-Kister equation. We observed a negative behavior for both ionic liquids + water mixtures that can be attributed to a shrinkage of the mixtures.
\end{abstract}

Keywords: Density, viscosity, excess properties, protic ionic liquid.

\section{INTRODUCTION}

Ionic liquids are defined as salts that have a low melting point (Kurnia et al., 2011). Historically, ethylammonium nitrate was the first ionic liquid studied, in the beginning of the 20th century. Ionic liquids are considered as potential environmentally friendly solvents (Xuemei et al. 2013), presenting low vapor pressure in comparison to traditional volatile organic solvents widely used in chemical industries. There are other important characteristics that take advantage of their use, as follows: low melting temperature, favorable solvation behavior, high ionic conductivity, stability in air, and modification of selectivity in chemical reactions, which open new possibilities in various industrial fields such as catalysis, separation techniques, and electrochemical device building (Iglesias et al., 2008).

Ionic liquids are produced from the combination of cations, that includes compounds based on substituted amines, and organic acids with different numbers of carbon atoms as anions in order to adapt more 
effectively to a specific process, e.g., separation processes and catalytic reactions (Peric et al., 2014). Generally, ionic liquids are divided into two large families, aprotic and protic.

Aprotic ionic liquids (AIL's) are constituted primarily of imidazolium cations. Nevertheless, their use becomes difficult in industrial process applications due to their high cost (Bourbigou-Olivier et al., 2010). On the other hand, protic ionic liquids (PIL's) are produced by proton transfer of a Brønsted acid to a Brønsted base (cation with amino group). For this reason, their production could be characterized as low cost. In addition, their syntheses are less complex and, depending on the process, can be recycled and reused (Alvarez, 2010).

Thermodynamic and transport properties are very important experimental data for design and from a theoretical point of view. The addition of a solvent in a liquid mixture can dramatically increase or decrease the density and viscosity in these systems (Alvarez et al., 2011). Various technological processes involving IL's need the knowledge of these mixture properties with the addition of other solvents. To understand the interactions of their constituent cations and anions with water, the behavior of IL's when mixed with various solvents is of utmost importance. The mixing deviation from ideality is useful in the study of molecular interactions and is of great interest for industrial applications, e.g., polar solvent extraction processes and Aqueous Biphasic Systems (ABS). The data of densities and viscosities for 2-hydroxydiethanolamine formate (2-HDEAF), 2-hydroxydiethanolamine acetate (2-HDEAA), and water and their binary mixtures (2-HDEAF + water and 2-HDEAA + water) at temperatures ranging between (293.15 and 343.15) $\mathrm{K}$ have been experimentally determined. It is important to note that these data were not found in the literature.

\section{EXPERIMENTAL}

\section{Materials}

Formic acid (purity $\geq 0.85$ in mass fraction), acetic acid (purity $\geq 0.99$ in mass fraction), diethanolamine (purity $\geq 0.99$ in mass fraction) were used without further purification and purchased from VETEC. Deionized water was used.

\section{Synthesis and characterization of ionic liquids}

The PIL's analyzed in the present study, 2-hydroxydiethanolamine formate (2-HDEAF) and 2-hydroxydiethanolamine acetate (2-HDEAA) (Peric et al., 2013) were obtained by equimolar neutralization reaction of diethanolamine with formic and acetic acids, respectively, as described in detail by AlvarezAlvarez (2010).

The system for the production of PIL's was constituted of a glass three-necked flask equipped with thermocouple, a funnel and a condenser. The acid was added dropwise to the flask with diethanolamine. After complete addition of the acid, the reaction remained under agitation for at least 24 hours for the formation of a viscous and slightly yellow product. The resulting liquids were dried under a vacuum pump for $48 \mathrm{~h}$ and $20 \mathrm{kPa}$ in order to reduce the water content as much as possible, and were stored in a dark bottle (Alvarez et al., 2011). It is important to mention that ionic liquid densities have been measured before and after a drying procedure, in order to have a roughly idea of the effect of water content. It has been found that the amount of water in the ionic liquids produced has negligible effect. Figure 1 shows the chemical structures of the ionic liquids studied.

\begin{tabular}{|c|c|}
\hline $\begin{array}{l}\text { 2-hydroxydiethanolamine formate } \\
\text { (2-HDEAF) }\end{array}$ & $\mathrm{HO}$ \\
\hline $\begin{array}{l}\text { 2-hydroxydiethanolamine acetate } \\
\text { (2-HDEAA) }\end{array}$ & $\mathrm{OH}_{\mathrm{O}^{-}}^{\mathrm{H}_{3} \mathrm{C}}$ \\
\hline
\end{tabular}

Figure 1. Structures and abbreviations of the analyzed PILs. 


\section{Methods}

The binary mixtures containing ionic liquid and water were prepared by mass weight percent and they were kept in sealed glass bottles to avoid contamination and evaporation of the components. 2-HDEAF and 2-HDEAA ionic liquids were completely solubilized in water. All samples were prepared using an electronic scale (Shimadzu, model AY220) with uncertainty of \pm $1 \times 10^{-4} \mathrm{~g}$. All mixtures were prepared in a composition range from 0.1 to 0.9 . The uncertainty in experimental mole fraction was estimated to be approximately $\pm 1,7$ $\times 10^{-3}$.

Densities and viscosities of the pure liquids (2-HDEAF, 2-HDEAA and water) and their binary mixtures (2-HDEAF + water, 2-HDEAA + water) were experimentally determined by using a viscodensimeter (SVM 3000, Anton Paar). A $5 \mathrm{~mL}$ sample was injected into the equipment by using a syringe in the experimental measurements. Both measurements were realized simultaneously and in duplicate by the equipment itself. The viscodensimeter presented an accuracy of $\pm 0.01 \mathrm{~K}$ for temperature, $\pm 0.0005 \mathrm{~g} \cdot \mathrm{cm}^{-3}$ for density, and for relative viscosity $\pm 0.35 \%$. After analyses performed in triplicate, it was observed that the temperature measurement had an experimental uncertainty of $\pm 0.01 \mathrm{~K}$ for temperature, \pm 0.00002 $\mathrm{g} \cdot \mathrm{cm}^{-3}$ for density, and $\pm 0.0006 \mathrm{mPa} \cdot \mathrm{s}$ for viscosity.

\section{Thermodynamics correlation}

The temperature dependence of densities of the pure components and binary mixtures were fitted using the linear equation:

$$
\rho=A_{0}+A_{1} T
$$

where $\rho\left(\mathrm{g} \cdot \mathrm{cm}^{-3}\right)$ is the density and $A_{0}$ and $A_{1}$ are the coefficients.

The excess molar volume $\left(V^{E}\right)$ was calculated from the density of pure component, $\rho_{\mathrm{i}}$ and of binary mixtures $\rho$, by:

$$
V^{E}=\sum x_{i} M_{i}\left(\rho^{-1}-\rho_{i}^{-1}\right)
$$

where $x_{i}$ and $M i$ are the mole fraction and molar mass of pure component $i$ respectively.

Experimental viscosity data were used to calculate the deviation of viscosity $(\Delta \eta)$ of the binary mixtures, by:

$$
\Delta \eta=\eta-\sum_{i=1}^{n} x_{i} \eta_{i}
$$

where $\eta$ is the dynamic viscosity of the mixture; $\eta_{i}$ and $x_{i}$ denote viscosities and mass fractions of pure components, respectively.

Density $(\rho)$ and viscosity $(\eta)$ data were used to derive the excess Gibbs free energy of activation $\left(\mathrm{G}^{*} \mathrm{E}\right)$ by:

$$
G^{*}=R T\left[\ln (\eta V)-\sum_{i=1}^{2} x_{i} \ln \left(\eta_{i} V_{i}\right)\right]
$$

where $R$ is the universal gas constant; $T$ is the absolute temperature; $V$ and $V_{i}$ are the molar volumes of the binary blends and pseudo-pure compounds, respectively.

$$
M^{E}=x_{1}\left(1-x_{1}\right) \sum_{j=0}^{K} A_{j}\left(1-2 x_{i}\right)^{j}
$$

The excess properties, $V^{E}, \Delta \eta$ and $G^{* E}$ were correlated by the Redlich-Kister polynomial equation: where $M^{E}$ is the excess property or deviation, $x_{1}$ is the mole fraction, $A j$ is a parameter, and $k$ is the degree of the polynomial expansion. $A_{j}$ values were obtained using a nonlinear least-squares fitting procedure.

$$
\sigma\left(M^{E}\right)=\sqrt{\frac{\sum\left(M_{\exp }^{E}-M_{a d j}^{E}\right)^{2}}{(n-p)}}
$$

The corresponding standard deviations $\sigma\left(M^{E}\right)$ were calculated by:

where $M_{\text {exp }}$ is the experimental excess property and $M_{c a l}$ is the calculated (adjusted) excess property, $n$ is the number of experimental points, and $p$ is the number of parameters retained in the respective equation.

\section{RESULTS AND DISCUSSION}

\section{Density and excess molar volume}

Table 1 presents the experimental density data of pure protic ionic liquid from this work and the literature at $293.15 \mathrm{~K}$. To proving the chemical structures was been realized a NMR of the studied ionic liquids.

Table 1. Densities of the ionic liquids $2-\mathrm{HDEAF}$ and 2- HDEAA at $293.15 \mathrm{~K}$.

\begin{tabular}{lcc}
\hline Chemical & $\boldsymbol{\rho}_{\text {experimental }}$ & $\mathbf{P}_{\text {literature }}$ \\
\hline HDEAF & 1.2112 & - \\
HDEAA & 1.1777 & $1.1786^{\text {(Santos et al., 2016) }}$ \\
\hline
\end{tabular}


Table 2 and Figures 2 a and 2 b depict density data for pure 2-HDEAF + water and 2-HDEAA + water from $\mathrm{T}=(293.15$ to 343.15$) \mathrm{K}$ and atmospheric pressure. From these data it is possible to state that 2-HDEAF + water and 2-HDEAA + water binary systems present a volumetric behaviour of regular liquids, i.e., decreasing with increasing temperature, in a linear behaviour. Observing various compositions at a single temperature, it can be seen that increasing water composition in the binary mixture causes a decrease in density.

Table 3 and Figures 3 a and $3 \mathrm{~b}$ show the excess molar volumes for the systems 2-HDEAF + water and 2-HDEAA + water, from $\mathrm{T}=(293.15$ to 343.15$)$ $\mathrm{K}$. It could be observed that, for both binary systems (2-HDEAF + water and 2-HDEAA + water) in the whole range of composition and for both temperature studied, a negative behavior is characterised. This negative excess molar volume can be attributed to strong interactions between ionic liquids (2-HDEAF and 2-HDEAA) and water and, as a result, a volume contraction. The same conclusion was obtained by Alvarez et al. (2011) by studying mixtures of 2-hydroxyethylammonium acetate with low molecular weight polar solvents. This behavior can be explained by the high dielectric constant of water. The maximum value in $V^{E}$ occurs between 0.7 and 0.8 mol fraction of water.

\section{Viscosity, deviation of viscosity and excess Gibbs free energy}

The experimental viscosities values of pure ionic liquids, water and binary mixtures at the various temperatures are listed in Table 4.

Table 2. Densities $(\rho)$ of the pure components (2-HDEAF, 2-HDEAA and water) and binary mixtures in the temperature range (293.15 to 343.15$) \mathrm{K}$ and at atmospheric pressure.

\begin{tabular}{|c|c|c|c|c|c|c|}
\hline \multicolumn{7}{|c|}{ Density $\left(\mathrm{g} \cdot \mathrm{cm}^{-3}\right)$} \\
\hline & \multicolumn{6}{|c|}{$T / K$} \\
\hline & 293.15 & 303.15 & 313.15 & 323.15 & 333.15 & 343.15 \\
\hline \multicolumn{7}{|c|}{ 2-HDEAF $\left(x_{2}\right)+$ water $\left(x_{1}\right)$} \\
\hline 2-HDEAF & 1.2112 & 1.2057 & 1.2002 & 1.1947 & 1.1893 & 1.1837 \\
\hline 0.2013 & 1.2053 & 1.1997 & 1.1944 & 1.1890 & 1.1836 & 1.1782 \\
\hline 0.2622 & 1.2040 & 1.1985 & 1.1932 & 1.1877 & 1.1823 & 1.1767 \\
\hline 0.4068 & 1.1961 & 1.1907 & 1.1852 & 1.1799 & 1.1741 & 1.1687 \\
\hline 0.4845 & 1.1946 & 1.1894 & 1.1837 & 1.1784 & 1.1729 & 1.1672 \\
\hline 0.6815 & 1.1753 & 1.1699 & 1.1646 & 1.1594 & 1.1537 & 1.1477 \\
\hline 0.7816 & 1.1560 & 1.1508 & 1.1454 & 1.1399 & 1.1344 & 1.1288 \\
\hline 0.8484 & 1.1334 & 1.1285 & 1.1234 & 1.1182 & 1.1126 & 1.1069 \\
\hline 0.9250 & 1.0899 & 1.0855 & 1.0808 & 1.0754 & 1.0702 & 1.0647 \\
\hline 0.9708 & 1.0430 & 1.0393 & 1.0352 & 1.0306 & 1.0256 & 1.0201 \\
\hline Water & 0.9984 & 0.9958 & 0.9923 & 0.9882 & 0.9833 & 0.9730 \\
\hline \multicolumn{7}{|c|}{ 2-HDEAA $\left(x_{2}\right)+$ water $\left(x_{\nu}\right)$} \\
\hline 2-HDEAA & 1.1777 & 1.1714 & 1.1650 & 1.1583 & 1.1517 & 1.1453 \\
\hline 0.1586 & 1.1779 & 1.1716 & 1.1652 & 1.1586 & 1.1521 & 1.1458 \\
\hline 0.2897 & 1.1760 & 1.1697 & 1.1632 & 1.1568 & 1.1503 & 1.1440 \\
\hline 0.4528 & 1.1733 & 1.1669 & 1.1606 & 1.1543 & 1.1482 & 1.1417 \\
\hline 0.5293 & 1.1693 & 1.1630 & 1.1570 & 1.1510 & 1.1448 & 1.1382 \\
\hline 0.6932 & 1.1608 & 1.1550 & 1.1490 & 1.1430 & 1.1368 & 1.1304 \\
\hline 0.8573 & 1.1291 & 1.1238 & 1.1181 & 1.1123 & 1.1066 & 1.1004 \\
\hline 0.9194 & 1.0968 & 1.0920 & 1.0869 & 1.0816 & 1.0760 & 1.0700 \\
\hline 0.9549 & 1.0650 & 1.0609 & 1.0565 & 1.0515 & 1.0463 & 1.0405 \\
\hline 0.9874 & 1.0187 & 1.0159 & 1.0123 & 1.0077 & 1.0028 & 0.9975 \\
\hline Water & 0.9984 & 0.9958 & 0.9923 & 0.9882 & 0.9833 & 0.9730 \\
\hline
\end{tabular}

Standard uncertainties are $\mathrm{u}(\rho)=0.00002 \mathrm{~g} \cdot \mathrm{cm}^{-3}$ and $\mathrm{u}(\mathrm{T})=0.01 \mathrm{~K}$ 

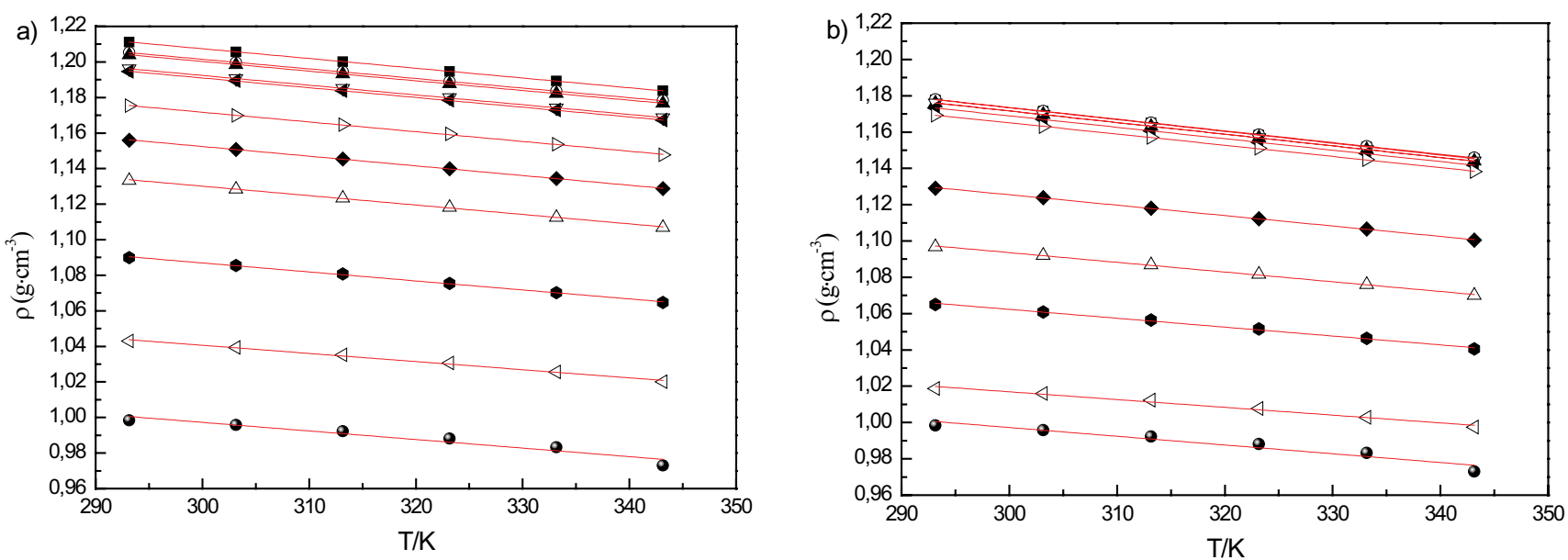

Figure 2: Densities of pure components and binary mixtures at different temperatures and compositions. a) 2-HDEAF + water mixture: $(\boldsymbol{\square}) x_{1=} 0 ;(\circ) x_{1}=0.2013 ;(\boldsymbol{\Delta}) x_{1}=0.2621 ;(\nabla) x_{1}=0.4430 ;(\boldsymbol{\Delta}) x_{1}=0.4845 ;(\triangleright) x$ $=0.6815 ;() x_{1}=0.7816 ;(\triangle) x_{1}=0.8484 ;(\bullet) x_{1}=0.9249 ;(\triangleleft) x_{1}=0.9708 ;(\bullet) x_{1}=1$. b) 2 -HDEAA + water mixture: $(\mathbf{\square}) x_{1=} 0 ;(\circ) x_{1}=0.1586 ;(\boldsymbol{\Delta}) x_{1}=0.2897 ;(\nabla) x_{1}=0.4528 ;(\varangle) x_{1}=0.5293 ;(\triangleright) x_{1}=0.6932 ;(\bullet) x_{1}=$ $0.8573 ;(\triangle) x_{1}=0.9194 ;(\bullet) x_{1}=0.9579 ;(\triangleleft) x_{1}=0.9874 ;(\bullet) x_{1}=1$.

Table 3. Excess molar volumes (VE) of the studied binary mixtures in the temperature range (293.15 to 343.15) $\mathrm{K}$ and at atmospheric pressure.

\begin{tabular}{|c|c|c|c|c|c|c|}
\hline \multicolumn{7}{|c|}{ Excess Molar Volume $\left(\mathrm{cm}^{3} / \mathrm{mol}^{-1}\right)$} \\
\hline & \multicolumn{6}{|c|}{$T / K$} \\
\hline$X$ & 293.15 & 303.15 & 313.15 & 323.15 & 333.15 & 343.15 \\
\hline \multicolumn{7}{|c|}{$2-H D E A F\left(x_{2}\right)+\operatorname{water}\left(x_{1}\right)$} \\
\hline 0.0000 & 0.0000 & 0.0000 & 0.0000 & 0.0000 & 0.0000 & 0.0000 \\
\hline 0.2013 & -0.1357 & -0.1183 & -0.1301 & -0.1355 & -0.1354 & -0.1731 \\
\hline 0.2622 & -0.2570 & -0.2463 & -0.2561 & -0.2525 & -0.2531 & -0.2796 \\
\hline 0.4068 & -0.4003 & -0.3905 & -0.3735 & -0.3677 & -0.2983 & -0.4022 \\
\hline 0.4845 & -0.5417 & -0.5409 & -0.5172 & -0.5234 & -0.5187 & -0.5618 \\
\hline 0.6815 & -0.6363 & -0.6125 & -0.6039 & -0.6072 & -0.5947 & -0.6445 \\
\hline 0.7816 & -0.6213 & -0.5984 & -0.5808 & -0.5679 & -0.5641 & -0.6410 \\
\hline 0.8484 & -0.5247 & -0.5046 & -0.4922 & -0.4859 & -0.4781 & -0.5570 \\
\hline 0.9250 & -0.3590 & -0.3412 & -0.3311 & -0.3142 & -0.3148 & -0.4041 \\
\hline 0.9708 & -0.1622 & -0.1498 & -0.1450 & -0.1407 & -0.1420 & -0.2326 \\
\hline 1.0000 & 0.0000 & 0.0000 & 0.0000 & 0.0000 & 0.0000 & 0.0000 \\
\hline \multicolumn{7}{|c|}{$2-\operatorname{HDEAA}\left(x_{2}\right)+\operatorname{water}\left(x_{1}\right)$} \\
\hline 0.0000 & 0.0000 & 0.0000 & 0.0000 & 0.0000 & 0.0000 & 0.0000 \\
\hline 0.1586 & -0.4558 & -0.4505 & -0.4474 & -0.4560 & -0.4673 & -0.4955 \\
\hline 0.2897 & -0.6450 & -0.6332 & -0.6165 & -0.6380 & -0.6462 & -0.6849 \\
\hline 0.4528 & -0.9295 & -0.9030 & -0.8973 & -0.9168 & -0.9515 & -0.9892 \\
\hline 0.5293 & -0.9209 & -0.8966 & -0.9058 & -0.9384 & -0.9604 & -0.9981 \\
\hline 0.6932 & -1.1226 & -1.1135 & -1.1098 & -1.1250 & -1.1373 & -1.2030 \\
\hline 0.8573 & -0.9284 & -0.9134 & -0.9017 & -0.9014 & -0.9152 & -0.9971 \\
\hline 0.9194 & -0.6547 & -0.6391 & -0.6318 & -0.6325 & -0.6381 & -0.7253 \\
\hline 0.9549 & -0.4078 & -0.3974 & -0.3965 & -0.3944 & -0.4015 & -0.4915 \\
\hline 0.9874 & -0.0801 & -0.0824 & -0.0856 & -0.0807 & -0.0843 & -0.1806 \\
\hline 1.0000 & 0.0000 & 0.0000 & 0.0000 & 0.0000 & 0.0000 & 0.0000 \\
\hline
\end{tabular}



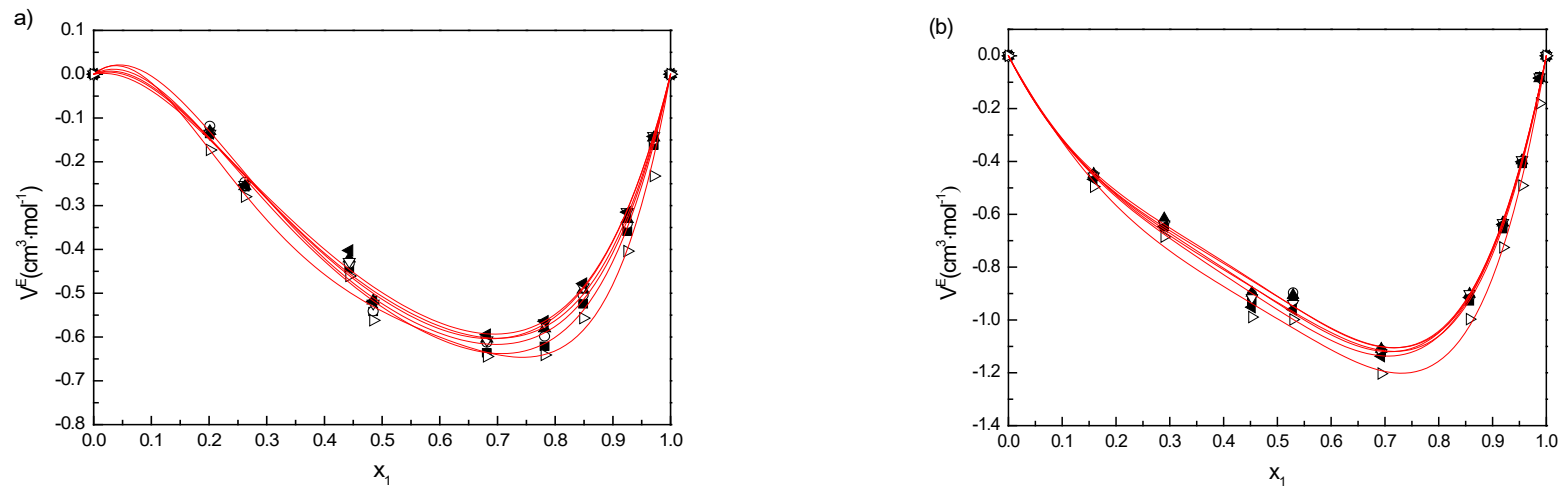

Figure 3. Excess molar volumes of the binary mixtures at different temperatures and compositions. (ロ) 293.15

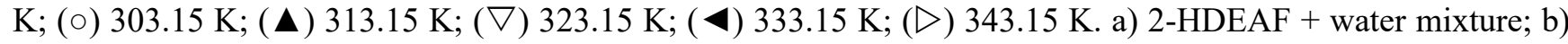
2-HDEAA + water mixture.

Table 4. Viscosity $(\eta)$ of the pure components (2-HDEAF, 2-HDEAA and water) and binary mixtures in the temperature range (293.15 to 343.15$) \mathrm{K}$ and at atmospheric pressure.

\begin{tabular}{|c|c|c|c|c|c|c|}
\hline \multicolumn{7}{|c|}{ Viscosity (mPa's) } \\
\hline & \multicolumn{6}{|c|}{$T / K$} \\
\hline$X$ & 293.15 & 303.15 & 313.15 & 323.15 & 333.15 & 343.15 \\
\hline \multicolumn{7}{|c|}{$2-H D E A F\left(x_{2}\right)+$ water $\left(x_{p}\right)$} \\
\hline 2-HDEAF & 470.90 & 241.95 & 135.00 & 82.246 & 52.983 & 35.910 \\
\hline 0.2013 & 329.02 & 172.48 & 99.278 & 61.446 & 40.386 & 27.824 \\
\hline 0.2622 & 243.17 & 131.68 & 77.499 & 48.977 & 32.781 & 22.959 \\
\hline 0.4068 & 132.61 & 75.655 & 46.592 & 30.628 & 21.220 & 15.339 \\
\hline 0.4845 & 112.26 & 65.084 & 40.722 & 27.104 & 18.984 & 13.859 \\
\hline 0.6815 & 36.232 & 23.182 & 15.798 & 11.307 & 8.4182 & 6.4966 \\
\hline 0.7816 & 16.089 & 11.045 & 7.9799 & 6.0085 & 4.6822 & 3.7546 \\
\hline 0.8484 & 8.1903 & 5.9267 & 4.4772 & 3.5061 & 2.8220 & 2.3309 \\
\hline 0.9250 & 3.2458 & 2.4958 & 1.9919 & 1.6410 & 1.3773 & 1.1756 \\
\hline 0.9708 & 1.6851 & 1.3419 & 1.1043 & 0.9306 & 0.7984 & 0.6951 \\
\hline Water & 0.9995 & 0.8187 & 0.6882 & 0.5831 & 0.5035 & 0.4509 \\
\hline \multicolumn{7}{|c|}{$2-H D E A A\left(x_{2}\right)+$ water $\left(x_{\nu}\right)$} \\
\hline 2-HDEAA & 5750.3 & 2248.3 & 1002.7 & 491.73 & 261.21 & 148.50 \\
\hline 0.1586 & 3625.3 & 1491.7 & 686.46 & 346.13 & 189.06 & 110.43 \\
\hline 0.2897 & 2207.9 & 946.14 & 452.01 & 236.33 & 133.32 & 80.199 \\
\hline 0.4528 & 1041.8 & 473.86 & 239.27 & 131.77 & 78.025 & 49.097 \\
\hline 0.5293 & 658.27 & 310.75 & 162.42 & 92.222 & 56.182 & 36.282 \\
\hline 0.6932 & 162.61 & 87.190 & 51.050 & 32.115 & 21.427 & 15.001 \\
\hline 0.8573 & 19.253 & 12.672 & 8.8359 & 6.4547 & 4.8944 & 3.8302 \\
\hline 0.9194 & 6.3624 & 4.5843 & 3.4421 & 2.6902 & 2.1670 & 1.7886 \\
\hline 0.9549 & 3.0274 & 2.3007 & 1.8181 & 1.4837 & 1.2361 & 1.0573 \\
\hline 0.9874 & 1.3702 & 1.0993 & 0.9188 & 0.7821 & 0.6763 & 0.5876 \\
\hline Water & 0.9995 & 0.8187 & 0.6882 & 0.5831 & 0.5035 & 0.4509 \\
\hline
\end{tabular}

Standard uncertainties are $\mathrm{u}(\mu)=0.0006 \mathrm{mPa} \cdot \mathrm{s}$ and $\mathrm{u}(\mathrm{T})=0.01 \mathrm{~K}$. 

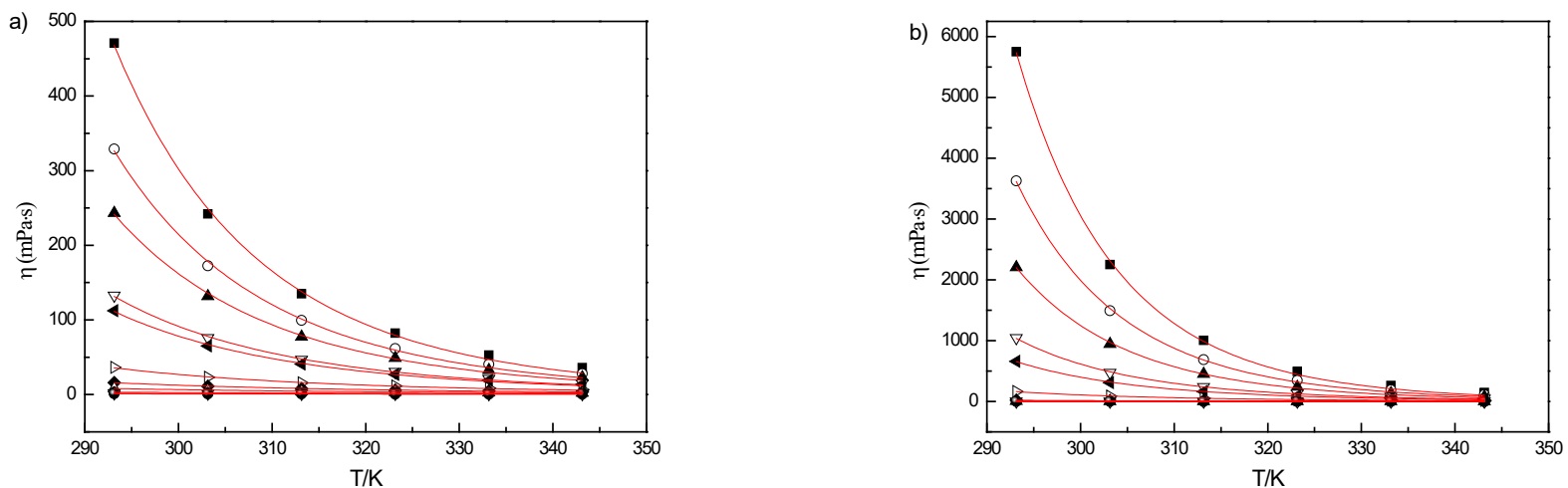

Figure 4. Viscosities of pure components and binary mixtures at different temperatures and compositions. a) 2-HDEAF + water mixture: $(\boldsymbol{\square}) x_{1}=0 ;(\circ) x_{1}=0.2013 ;(\boldsymbol{\Delta}) x_{1}=0.2621 ;(\nabla) x_{1}=0.4430 ;(\varangle) x_{1}=0.4845 ;(\triangleright)$ $\left.x_{1}=0.6815 ;(\bullet) x_{1}=0.7816 ;(\triangle) x_{1}=0.8484 ;(\bullet) x_{1}=0.9249 ;(\triangleleft) x_{1}=0.9708 ;(\bullet) x_{1}=1 . \mathrm{b}\right) 2$-HDEAA + water mixture: $(\bullet) x_{1}=0 ;(\circ) x_{1}=0.1586 ;(\Delta) x_{1}=0.2897 ;(\nabla) x_{1}=0.4528 ;(\triangleleft) x_{1}=0.5293 ;(\triangleright) x_{1}=0.6932 ;(\diamond) x_{1}=$ $0.8573 ;(\triangle) x_{1}=0.9194 ;(\bullet) x_{1}=0.9579 ;(\triangleleft) x_{1}=0.9874 ;(\bullet) x_{1}=1$.

Table 5. Deviation of viscosity $(\Delta \eta)$ of the studied binary mixtures in the temperature range (293.15 to 343.15$) \mathrm{K}$ and at atmospheric pressure.

\begin{tabular}{|c|c|c|c|c|c|c|}
\hline \multicolumn{7}{|c|}{ Deviation of viscosity $(\mathrm{mPa} \cdot \mathrm{s})$} \\
\hline & \multicolumn{6}{|c|}{$T / K$} \\
\hline$X$ & 293.15 & 303.15 & 313.15 & 323.15 & 333.15 & 343.15 \\
\hline \multicolumn{7}{|c|}{ 2-HDEAF $\left(x_{2}\right)+$ water $\left(x_{p}\right)$} \\
\hline 0.0000 & 0.0000 & 0.0000 & 0.0000 & 0.0000 & 0.0000 & 0.0000 \\
\hline 0.2013 & -47.268 & -20.919 & -8.679 & -4.358 & -2.030 & -0.946 \\
\hline 0.2622 & -104.541 & -47.055 & -22.290 & -11.860 & -6.444 & -3.655 \\
\hline 0.4068 & -130.110 & -59.467 & -28.904 & -15.439 & -8.513 & -4.862 \\
\hline 0.4845 & -130.956 & -60.029 & -29.199 & -15.573 & -8.571 & -4.870 \\
\hline 0.6815 & -114.438 & -54.441 & -27.671 & -15.287 & -8.801 & -5.249 \\
\hline 0.7816 & -87.520 & -42.428 & -22.037 & -12.407 & -7.281 & -4.439 \\
\hline 0.8484 & -64.039 & -31.444 & -16.571 & -9.456 & -5.637 & -3.495 \\
\hline 0.9250 & -33.008 & -16.414 & -8.773 & -5.069 & -3.064 & -1.936 \\
\hline 0.9708 & -13.017 & -6.509 & -3.501 & -2.034 & -1.235 & -0.790 \\
\hline 1.0000 & 0.0000 & 0.0000 & 0.0000 & 0.0000 & 0.0000 & 0.0000 \\
\hline \multicolumn{7}{|c|}{ 2-HDEAA $\left(x_{2}\right)+$ water $\left(x_{\nu}\right)$} \\
\hline 0.0000 & 0.0000 & 0.0000 & 0.0000 & 0.0000 & 0.0000 & 0.0000 \\
\hline 0.1586 & -1212.984 & -400.108 & -157.338 & -67.753 & -30.870 & -14.668 \\
\hline 0.2897 & -1876.611 & -651.031 & -260.458 & -113.214 & -52.493 & -25.557 \\
\hline 0.4528 & -2105.070 & -756.803 & -309.831 & -137.740 & -65.348 & -32.599 \\
\hline 0.5293 & -2049.009 & -748.085 & -310.091 & -139.766 & -67.294 & -34.134 \\
\hline 0.6932 & -1602.293 & -603.286 & -257.270 & -119.434 & -59.395 & -31.234 \\
\hline 0.8573 & -802.337 & -309.079 & -135.129 & -64.577 & -33.231 & -18.199 \\
\hline 0.9194 & -457.763 & -177.440 & -78.241 & -37.829 & -19.779 & -11.068 \\
\hline 0.9549 & -257.301 & -100.063 & -44.358 & -21.640 & -11.485 & -6.5700 \\
\hline 1.0000 & 0.0000 & 0.0000 & 0.0000 & 0.0000 & 0.0000 & 0.0000 \\
\hline
\end{tabular}



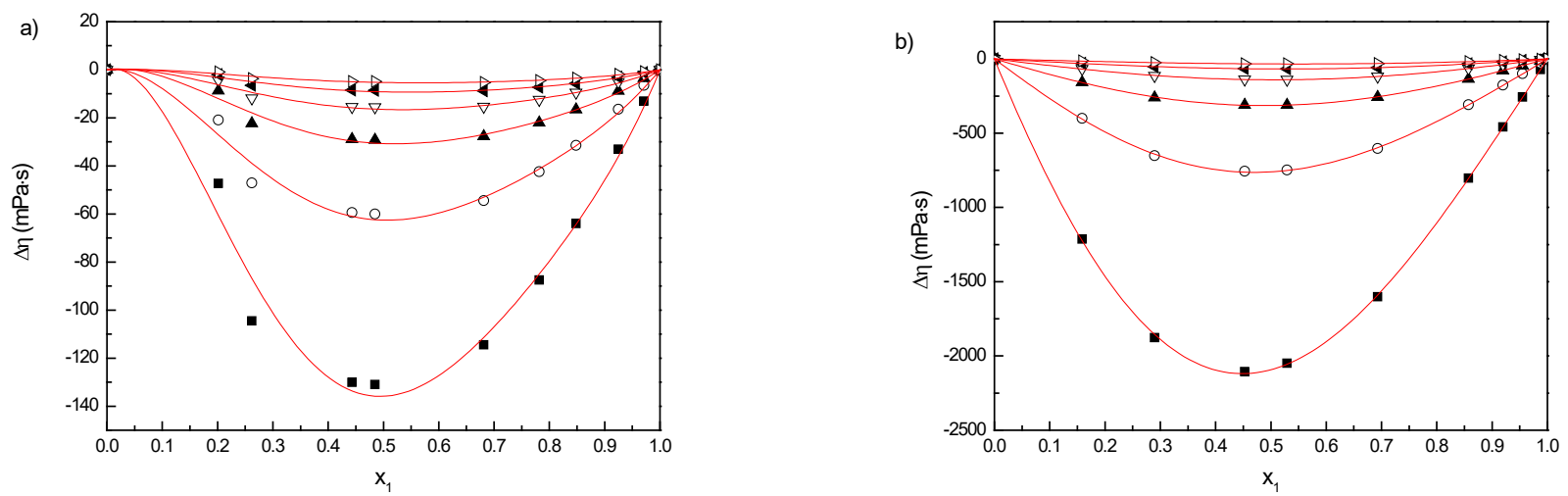

Figure 5. Deviation of viscosity $(\Delta \eta)$ of the studied binary mixtures in the temperature range (293.15 to 343.15$) \mathrm{K}$

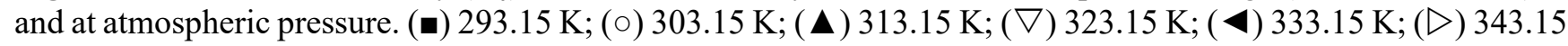
K. a) 2-HDEAF + water mixture; b) 2-HDEAA + water mixture.

Table 6. Excess Gibbs free energy of activation $\left(G^{*}\right)$ of the studied binary mixtures in the temperature range (293.15 to 343.15$) \mathrm{K}$ and at atmospheric pressure.

\begin{tabular}{|c|c|c|c|c|c|c|}
\hline \multicolumn{7}{|c|}{ Excess molar Gibbs (KJ/mol) } \\
\hline & \multicolumn{6}{|c|}{$T / K$} \\
\hline$X$ & 293.15 & 303.15 & 313.15 & 323.15 & 333.15 & 343.15 \\
\hline \multicolumn{7}{|c|}{ 2-HDEAF $\left(x_{2}\right)+$ water $\left(x_{1}\right)$} \\
\hline 0.0000 & 0.0000 & 0.0000 & 0.0000 & 0.0000 & 0.0000 & 0.0000 \\
\hline 0.2013 & 2631.87 & 2536.60 & 2473.07 & 2430.21 & 2397.31 & 2343.14 \\
\hline 0.2622 & 2932.41 & 2857.80 & 2799.11 & 2768.03 & 2746.52 & 2698.17 \\
\hline 0.4430 & 4470.72 & 4368.18 & 4288.50 & 4247.20 & 4221.16 & 4151.94 \\
\hline 0.4845 & 4735.34 & 4633.39 & 4560.68 & 4524.02 & 4502.27 & 4434.90 \\
\hline 0.6815 & 5023.11 & 4949.48 & 4902.65 & 4894.23 & 4893.71 & 4828.88 \\
\hline 0.7816 & 4451.70 & 4418.56 & 4401.90 & 4424.24 & 4453.89 & 4398.70 \\
\hline 0.8484 & 3660.78 & 3654.81 & 3658.63 & 3701.97 & 3745.11 & 3696.44 \\
\hline 0.9250 & 2253.15 & 2261.88 & 2282.15 & 2349.65 & 2404.25 & 2343.52 \\
\hline 0.9708 & 1067.45 & 1069.05 & 1080.72 & 1127.82 & 1168.21 & 1088.09 \\
\hline 1.0000 & 0.0000 & 0.0000 & 0.0000 & 0.0000 & 0.0000 & 0.0000 \\
\hline \multicolumn{7}{|c|}{ 2-HDEAA $\left(x_{2}\right)+\operatorname{water}\left(x_{p}\right)$} \\
\hline 0.0000 & 0.0000 & 0.0000 & 0.0000 & 0.0000 & 0.0000 & 0.0000 \\
\hline 0.1586 & 2643.92 & 2568.03 & 2473.56 & 2394.59 & 2332.56 & 2264.37 \\
\hline 0.2897 & 4504.50 & 4350.99 & 4197.35 & 4078.37 & 3981.68 & 3869.33 \\
\hline 0.4528 & 6404.53 & 6163.47 & 5945.02 & 5782.33 & 5652.47 & 5498.20 \\
\hline 0.5293 & 6993.88 & 6724.44 & 6487.94 & 6312.01 & 6174.82 & 6006.96 \\
\hline 0.6932 & 7093.25 & 6842.81 & 6636.18 & 6500.40 & 6400.74 & 6247.49 \\
\hline 0.8573 & 5068.54 & 4960.23 & 4876.10 & 4845.27 & 4827.49 & 4722.30 \\
\hline 0.9194 & 3412.07 & 3359.10 & 3311.50 & 3320.28 & 3339.33 & 3257.09 \\
\hline 0.9549 & 2131.01 & 2101.46 & 2085.82 & 2119.25 & 2146.18 & 2081.75 \\
\hline 0.9874 & 630.24 & 622.90 & 649.31 & 701.98 & 744.21 & 637.51 \\
\hline 1.0000 & 0.0000 & 0.0000 & 0.0000 & 0.0000 & 0.0000 & 0.0000 \\
\hline
\end{tabular}



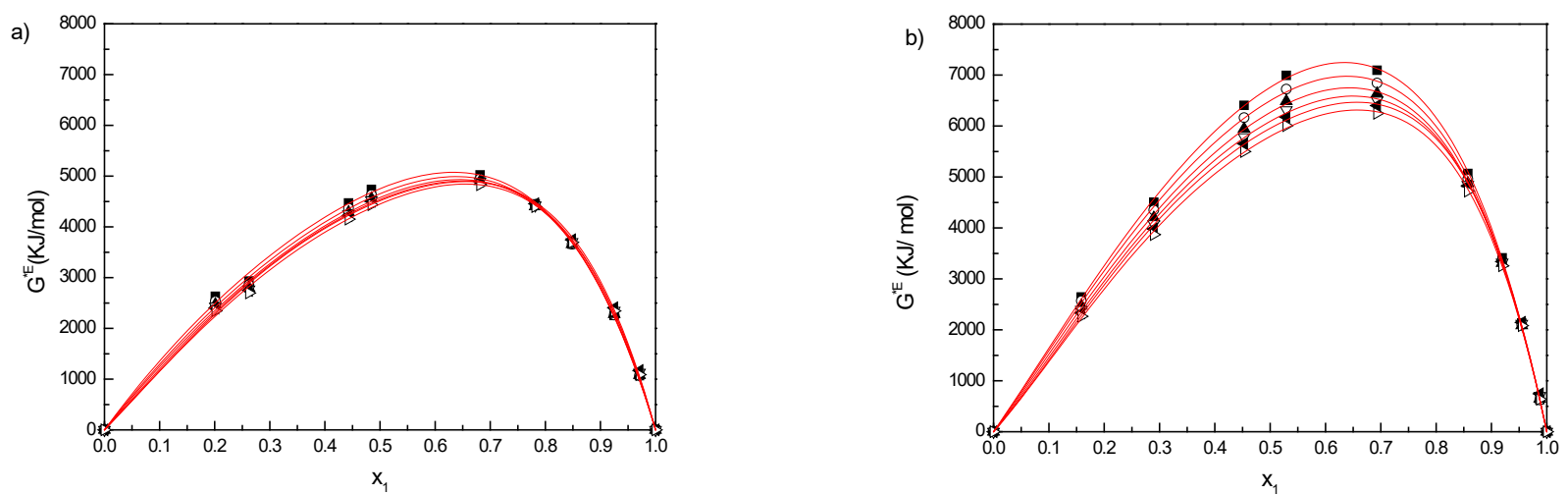

Figure 6. Excess molar Gibbs free energy of activation $\left(G^{*}\right)$ of the studied binary mixtures in the temperature

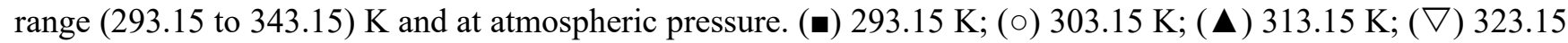
$\mathrm{K} ;(\varangle) 333.15 \mathrm{~K} ;(\triangleright) 343.15 \mathrm{~K}$. a) 2-HDEAF + water mixture; b) 2-HDEAA + water mixture.

Figures 4 (a) and 4 (b) show the behavior of the viscosity of the ionic liquids 2-HDEAF, 2-HDEAA, water and their mixtures, 2-HDEAF + water and 2-HDEAA + water, at different temperatures. The dependence of the viscosity with temperature shows an exponential behavior. The increase in temperature leads to a reduction of viscosity of mixtures with ionic liquids studied. As seen in Table 4, the greater the amount of water in the mixtures the lower the viscosity. It can be observed that the 2 -HDEAF + water mixture showed viscosity values lower than the values of the 2-HDEAA + water mixture; this difference may be due to the fact that the ionic liquid 2-HDEAF was produced from a lower carbon chain acid.

Deviation of viscosity for the binary mixtures of (2-HDEAF + water and 2-HDEAA + water) at different mole fractions from $\mathrm{T}=(293.15$ to 343.15$) \mathrm{K}$ and atmospheric pressure are listed in Table 5.

Figures 5(a) and 5(b) show that the $\Delta \eta$ values are negative for all temperatures and composition range for the mixtures studied. From these figures it can also be observed that, the higher the temperature, the less negative the deviations of viscosity values in both systems analyzed. According to Prausnitz (1986), $\Delta \eta$ of a mixture depends on molecular interactions, as well as on the size and shape of the molecules. For both figures, the minimum deviation in $\Delta \eta$ occurs between 0.4 and 0.5 mole fraction of water.

The excess Gibbs free energy of activation for the binary systems studied is reported in Table 6 .
Figures 6(a) and 6(b) show that $G^{*}$ presents positive values in all the temperature and composition range. According to Smith et al., (1996), positive values of $\mathrm{G}^{* \mathrm{E}}$ indicate specific interactions leading to complex formation through intermolecular hydrogen bonding interaction between unlike molecules compared to like molecules. For both figures, the largest excess molar Gibbs free energy of activation $\left(G^{* E}\right)$ is at 0.65 mole fraction of water.

The adjustment parameters, $A_{j}$, obtained with the Redlich-Kister polynomial equation and the standard deviation for the systems studied in $\mathrm{T}=(293.15$ to 343.15) $\mathrm{K}$ are presented in Table 7.

\section{CONCLUSIONS}

2-HDEAF and 2-HDEAA binary mixtures with water are completely miscible and exhibit a liquid ideal linear density-mole fraction and exponential viscosity-molar isotherms $[\mathrm{T}=(293.15$ and 343.15$)$ $\mathrm{K}]$. They present negative values for excess molar volume $\left(\mathrm{V}^{\mathrm{E}}\right)$ and viscosity deviation $(\Delta \eta)$ throughout the composition range, and present a minimum position around $x \approx 0.4-0.5$. Excess Gibbs free energy of activation presented positive values. All excess properties were fitted by the Redlich-Kister polynomial equation. This behavior suggests a shrinkage mixture with no symmetric isotherms, characteristics of a mixture that does not represent a regular solution, with no significant structural change takes place during the mixture. 
Table 7. Adjustment parameters of excess properties of (2-HDEAF + water ) and (2-HDEAA + water) binary mixtures as function of temperature with the Redlich-Kister equation together with the standard deviation $(\sigma)$.

\begin{tabular}{|c|c|c|c|c|c|c|}
\hline \multirow{2}{*}{ Parameters $\mathbf{A}_{\mathrm{j}}$} & \multicolumn{6}{|c|}{ Temperature (T/K) } \\
\hline & 293.15 & 303.15 & 313.15 & 323.15 & 333.15 & 343.15 \\
\hline \multicolumn{7}{|c|}{ Excess molar volume } \\
\hline \multicolumn{7}{|l|}{ 2-HDEAF + water } \\
\hline $\mathrm{A}_{0}$ & -2.12643 & -2.09601 & -2.02972 & -2.05557 & -1.99441 & -2.16445 \\
\hline $\mathrm{A}_{1}$ & 1.79160 & 1.71320 & 1.68377 & 1.71925 & 1.70771 & 1.37806 \\
\hline $\mathrm{A}_{2}$ & -0.56883 & -0.29727 & -0.49865 & -0.36774 & -0.5060 & -0.95081 \\
\hline $\mathrm{A}_{3}$ & 1.60526 & 1.69894 & 1.36948 & 1.11953 & 1.04171 & 2.84130 \\
\hline$\sigma$ & 0.36 & 0.35 & 0.33 & 0.32 & 0.32 & 0.37 \\
\hline \multicolumn{7}{|c|}{ 2-HDEAA+water } \\
\hline $\mathrm{A}_{0}$ & -3.73348 & -3.6453 & -3.64023 & -3.74633 & -3.84319 & -3.98187 \\
\hline $\mathrm{A}_{1}$ & 2.44644 & 2.53128 & 2.62815 & 2.61518 & 2.57545 & 2.42890 \\
\hline $\mathrm{A}_{2}$ & -3.41518 & -3.47405 & -3.36817 & -3.23608 & -3.16785 & -3.88892 \\
\hline $\mathrm{A}_{3}$ & 0.92805 & 0.59458 & 0.3918 & 0.33864 & 0.48902 & 1.79091 \\
\hline$\sigma$ & 0.38 & 0.37 & 0.38 & 0.37 & 0.38 & 0.43 \\
\hline \multicolumn{7}{|c|}{ Deviation of viscosity } \\
\hline \multicolumn{7}{|c|}{ 2-HDEAF+ water } \\
\hline $\mathrm{A}_{0}$ & -543.528 & -250.1761 & -122.847 & -65.9784 & -36.7009 & -21.1202 \\
\hline $\mathrm{A}_{1}$ & -20.2807 & 10.2840 & 16.0261 & 12.6246 & 10.0230 & 7.38721 \\
\hline $\mathrm{A}_{2}$ & 298.912 & 126.199 & 63.3994 & 30.9889 & 16.5867 & 8.75507 \\
\hline $\mathrm{A}_{3}$ & 340.669 & 145.097 & 76.4025 & 40.9607 & 24.1777 & 15.2022 \\
\hline$\sigma$ & 7.86 & 3.62 & 5.54 & 1.10 & 0.67 & 3.32 \\
\hline \multicolumn{7}{|l|}{ 2-HDEAA+water } \\
\hline $\mathrm{A}_{0}$ & -8369.94 & -3.042 .07 & -1.255 .24 & -562.577 & -269.361 & -135.786 \\
\hline$A_{1}$ & -2003.72 & -427.309 & -72.6578 & 16.138 & 31.780 & 28.934 \\
\hline $\mathrm{A}_{2}$ & 960.148 & 519.665 & 210.7525 & 82.267 & 31.998 & 10.703 \\
\hline $\mathrm{A}_{3}$ & 358.739 & 169.461 & 34.0407 & -5.280 & -6.650 & -2.312 \\
\hline$\sigma$ & 10.53 & 4.74 & 2.04 & 2.03 & 0.56 & 0.43 \\
\hline \multicolumn{7}{|c|}{ Excess Gibbs free energy of activation } \\
\hline \multicolumn{7}{|c|}{ 2-HDEAF + water } \\
\hline $\mathrm{A}_{0}$ & 19.007 & 18.608 & 18.309 & 18.151 & 18.055 & 17.802 \\
\hline $\mathrm{A}_{1}$ & -8.908 & -8.938 & -8.984 & -8.877 & -8.825 & -9.127 \\
\hline $\mathrm{A}_{2}$ & 6.223 & 6.352 & 6.580 & 6.953 & 7.256 & 7.035 \\
\hline $\mathrm{A}_{3}$ & -1.558 & -2.279 & -2.870 & -4.277 & -5.405 & -4.230 \\
\hline$\sigma$ & 81.56 & 74.64 & 72.94 & 75.35 & 77.12 & 63.47 \\
\hline \multicolumn{7}{|l|}{ 2-HDEAA+water } \\
\hline $\mathrm{A}_{0}$ & 27.035 & 25.987 & 25.062 & 24.367 & 23.819 & 23.185 \\
\hline $\mathrm{A}_{1}$ & -13.519 & -12.888 & -12.485 & -12.149 & -11.949 & -11.933 \\
\hline $\mathrm{A}_{2}$ & 6.693 & 7.286 & 7.697 & 8.275 & 8.806 & 8.650 \\
\hline $\mathrm{A}_{3}$ & -4.461 & -5.203 & -5.999 & -7.337 & -8.362 & -7.602 \\
\hline$\sigma$ & 40.81 & 40.78 & 40.94 & 49.75 & 58.69 & 41.38 \\
\hline
\end{tabular}




\section{NOMENCLATURE}

$\begin{array}{ll}A_{j} & \begin{array}{l}\text { adjustable parameter Redlich-Kister } \\ \text { equation }\end{array} \\ A_{0,} A_{1} & \begin{array}{l}\text { specific temperature coefficients } \\ \text { degree of the polynomial expansion }\end{array} \\ \mathrm{M}_{i} & \text { molar mass of component i } \\ N & \text { number of experimental points } \\ P & \text { number of parameters } \\ T & \text { Temperature } \\ V_{a d j}{ }^{E} & \text { excess molar volume adjusted } \\ V_{\text {exp }} & \text { excess molar volume experimental } \\ V^{E} & \text { excess molar volume } \\ W & \text { massic fraction } \\ X & \text { mole fraction } \\ \rho & \text { density } \\ \Sigma & \text { standard deviation } \\ \eta & \text { viscosity }\end{array}$

\section{REFERENCES}

Alvarez - Alvarez, V. H., Termodinâmica e aplicações de líquidos iônicos. Ph. D. Thesis (in Portuguese), University of Campinas (2010).

Alvarez, V. H., Mattedi, S., Martin-Pastor, M., Aznar, M. and Iglesias, M., Thermophysical properties of binary mixtures of \{ionic liquid 2-hydroxy ethylammonium acetate + (water, methanol, or ethanol)\}. J. Chem. Thermodyn., 43, 997-1010 (2011).

Iglesias, M., Torres, A., Gonzalez-Olmos, R. and Salvatierra, D., Effect of temperature on mixing thermodynamics of a new ionic liquid: \{2-Hydroxy ethylammoniumformate (2-HEAF) + short hydroxylic solvents\}. J. Chem. Thermodyn., 40, 119-133 (2008).
Kurnia, K. A., Taib, M. M. and Murugesan, T., Densities, refractives indices and excess molar volumes for binary mixtures of protic Ionic liquids with methanol at $\mathrm{T}=293.15$ to $313.15 \mathrm{~K}$. J. Mol. Liq., 159, 211-219 (2011).

Olivier-Bourbigou, H., Magna, L. and Morvan, D., Ionic liquids and catalysis: recent progress from knowledge to applications. Appl. Catal. A., 373, 1-53 (2010).

Peric, B., ; Sierra, J. Martí, E., Cruanas, R., Garau, M. A., Arning, J., Bottin-Weber, U and Stolte,S., (Eco)toxicity and biodegradability of selected protic and aprotic ionic liquids. J. Hazard. Mater., 261, 99- 105 (2013).

Peric, B., Sierra, J., Martí, E., Cruañas, R. and Garau, M. A., A comparative study of the terrestrial ecotoxicity of selected protic and aprotic ionic liquids. Chemosphere, 108, 418-425 (2014).

Prausnitz, J.M., Lichtenthaler, R. N. and Azevedo, E.G., Molecular Thermodynamics of Fluid-Phase Equilibria. Prentice-Hall, New Jersey (1986).

Redlich, O. and Kister, A. T., Algebraic representation of thermodynamics properties and the classification of solutions. Ind. Eng. Chem., 40, 345-348 (1948).

Santos, D., Lourenço, E., Santos, M. F. C., Franceschi, E., Dariva, C., Barison, A., Zuber, A., Castier, M. and Mattedi, S., Volumetric properties of binary aqueous solutions of protic ionic liquids based on bis (2-hydroxyethyl) ammonium. J. Mol. Liq., 222, 867-872, 2016.

Smith, J. M., Van Ness, H. C. and Abbott, M., Introduction to Chemical Engineering Thermodynamics. McGraw-Hill, New York (1996).

Xuemei, L. I., Chong, S. and Chunxi, L., Effect of Mono- and Di- ethanolammonium Formate ionic Liquids on the Volatility of Water, Ethanol, and Methanol, Chem. Eng. Thermodynamics, 21, 11621171 (2013) 
